\title{
AUDIT-STAFF SCHEDULING: AN HIERARCHICAL APPROACH
}

\author{
Frank Salewski, Christian-Albrechts-Universität Kiel \\ Andreas Drexl, Christian-Albrechts-Universität Kiel
}

Traditional audit-staff scheduling models are single-level models which try to construct a direct assignment of auditors to audit tasks and periods. By contrast, an empirical investigation among 200 of the biggest audit companies in Germany shows that the process of audit-staff scheduling usually is divided into three different levels [3]. While the names of these levels, viz. medium-lerm, medium-to-short-term, and short-term planning, refer to their differing planning horizons, also clear distinctions can be made in terms of organizational echelon involved, length of planning periods, degree of aggregation of the audit tasks, degree of detail of the required information, and decision objectives. Furthermore, the results of a more aggregated level are used as input to a more disaggregated level. The levels can be characterized as follows:

The medium-lerm planning [4] assigns teams of auditors to audit engagements. It constructs a schedule containing all the engagements' phases, e.g. preliminary, intermediate and final audit, and determines the workload per auditor and week - on the basis of periods of forty hours - over a planning horizon of between three and twelve months

The medium-1o-short-1erm planning [1] disaggregates the results of the medium-term level for one week and all auditors. The outcome is a schedule that specifies for each auditor - on the basis of periods of four hours - all the phases in which the auditor is involved in the considered week.

The short-term planning [2] is based upon the results of the medium-to-short-term level for one week and one phase. It assigns the auditors involved in the auditing of that phase in the considered week to the corresponding audit tasks and schedules them on the basis of periods of one hour.

With respect to those practical requirements we present for each level an appropriate model. The models are formulated in terms of binary optimization; they are closely related to resource-constrained project scheduling. Finally, we introduce some consistency relations and assumptions about parameter values to guarantee feasibility on the more disaggregated levels.

\section{References}

[1] Salewski, F., T. Bartsch, E. Pesch (1993): Auftragsterminierung für die taktisch-operative Personaleinsatzplanung in Wirtschaftsprüfungsgesellschaften, Discussion Paper, Universität Kiel.

[2] Salewski, F., L. Böttcher, A. Drexl (1993): Prüffeldorientierte Zuordnung von Prüfern für die operative Personaleinsatzplanung in Wirtschaftsprüfungsgesellschaften, Discussion Paper, Universität Kiel.

[3] Salewski, F., A. Drexl (1993): Personaleinsatzplanung in Wirtschaftsprüfungsgesellschaften - Bestandsaufnahme und konzeptioneller Ansatz, to appear in: Zeitschrift furr Betriebswirtschaft

[4] Salewski, F., A. Schirmer, A. Drexl (1993): Auftragsorientierte Bildung von Prüferteams für die taktische Personaleinsatzplanung in Wirtschaftsprüfungsgesellschaften, Discussion Paper, Universität Kiel. 